\title{
Effect of Bone Marrow-Derived Mesenchymal Stem Cells on Ischaemic-Reperfused Hearts in Adult Rats with Established Chronic Kidney Disease
}

\author{
Gehane M. Hamed ${ }^{1}$, Wessam E. Morsy ${ }^{1}$, Manal S. Abd-El Hamid ${ }^{1}$, \\ Arwa Abd el moniem Hassan', Fatma A. Abu Zahra ${ }^{2}$ \\ ${ }^{1}$ Department of Physiology, Faculty of Medicine, Ain Shams University, Cairo, Egypt \\ ${ }^{2}$ Department of Biochemistry, Medical Research Center, Ain Shams University, Cairo, Egypt
}

\begin{abstract}
Background and Objectives: Bone marrow-derived mesenchymal stem cells (BM-MSCs) are adult multipotent non-haematopoietic stem cells that have regeneration potential. The current study aimed to detect the ability of BM-MSCs to improve kidney and cardiac functions in adult rats with established chronic kidney disease.

Methods: Rats were divided into sham-operated control, untreated sub totally nephrectomised and treated sub totally nephrectomised groups. Body weight, kidney and cardiac tissue weights, plasma creatinine and urea levels and arterial blood pressure were measured. ECG was recorded, and an in vitro isolated heart study was performed.

Results: Stem cell treatment decreased the elevated plasma creatinine and urea levels and decreased systolic, diastolic and mean arterial blood pressure values. These changes were accompanied by a decrease in glomerular hypertrophy with apparent normal renal parenchyma. Additionally, BM-MSCs shortened Q-To and Q-Tc intervals, all time to peak tension values, the half relaxation value at $30 \mathrm{~min}$ of reperfusion and the contraction time at 15 and $30 \mathrm{~min}$ of reperfusion. Moreover, stem cell treatment significantly increased the heart rate, QRS voltage, the peak tension at the 15- and 30-min reperfusion time points and the peak tension per left ventricle at the 30-min reperfusion time point compared to the pre-ischaemia baseline. BM-MSCs resolve inter muscular oedema and lead to the re-appearance of normal cardiomyocytes. This improvement occurs with the observations of BM-MSCs in renal and heart tissues. Conclusions: BM-MSCs can attenuate chronic kidney disease progression and the associated cardiac electrophysiological and inotropic dysfunction.
\end{abstract}

Keywords: Chronic kidney disease, Nephrectomy, Bone marrow-derived stem cells, Isolated perfused heart study

Received: November 21, 2018, Revised: March 7, 2019,

Accepted: March 8, 2019, Published online: April 30, 2019

Correspondence to Fatma A. Abu Zahra

Department of Biochemistry, Medical Research Center, Ain Shams

University, El-Abaseya, Cairo 11566, Egypt

Tel: +2 01227402746, Fax: +2 24346671

E-mail: f_abu_zahra@hotmail.com

(c) This is an open-access article distributed under the terms of the Creative Commons Attribution Non-Commercial License (http://creativecommons.org/ licenses/by-nc/4.0/), which permits unrestricted non-commercial use, distribution, and reproduction in any medium, provided the original work is properly cited.

Copyright (c) 2019 by the Korean Society for Stem Cell Research

\section{Introduction}

Chronic kidney disease (CKD) is a global health burden and an independent risk factor for cardiovascular disease (CVD) (1). CKD is characterized by reduced nephron number, intra-glomerular hypertension (2), oxidative stress induction and interstitial inflammation with subsequent fibrosis (3). CKD is associated with sustained activation of the renin-angiotensin system (RAS), which augments renal inflammatory and pro-oxidant states and affects the cardiovascular system, inducing vascular resistance, arterial calcification, cardiovascular remodelling and inflam- 
mation (4).

Bone marrow-derived mesenchymal stem cells (BMMSCs) are adult multipotent non-haematopoietic stem cells that have potential roles in regeneration and tissue repair (5) and can be obtained and cultured without signifi cant ethical concerns (6). Additionally, MSCs have mitogenic, anti-apoptotic and angiogenic influences (7).

MSCs have been used in some acute renal failure models, such as in glycerol-induced ARF or in renal ischae$\mathrm{mic} /$ reperfusion, and were able to differentiate into tubular epithelial cells and to promote epithelial proliferation (8). In addition, Villanueva et al. (9) added that MSCs were able to attenuate glomerulosclerosis, interstitial fibrosis and the progression of CKD in rats.

In contrast, Gheisari et al. (10) could not confirm the beneficial or protective effects of MSCs in chemically induced AKI by glycerol and cisplatin. Huuskes et al. (11) claimed that although MSCs can accelerate renal repair following acute injury, the establishment of fibrosis during CKD may affect their regeneration capacity.

Therefore, the current study was planned to detect the ability of BM-MSCs to improve kidney function and cardiac function in adult rats with established CKD.

\section{Materials and Methods}

\section{Animals}

This study was performed on female adult albino rats weighing 160 200 gm at the start of the study that were purchased from the Egyptian Organization for Biological Products and Vaccines (VACSERA). Rats were kept in the Animal House of the Physiology Department, Faculty of Medicine, Ain Shams University under standard boarding conditions. Food and water access were provided ad libitum.

\section{Ethics declarations}

Ethical standards were adhered to in this research. In this work, animals were not exposed to unnecessary pain or stress, and animal manipulation was performed with maximal care and hygiene. The surgical procedure was performed under anaesthesia to avoid the induction of pain in animals. Disposal of the animal remains was achieved by incineration.

This work was approved by the Ain Shams Faculty of Medicine Research Ethics Committee under Federal Wide Assurance number 000017585.

\section{Experimental groups}

Rats were allocated into 3 groups containing 15 rats each.

Group I: Sham-operated control group that was supplemented with a single I.V. infusion of phosphate buffer solution in the rat tail vein for 4 weeks.

Group II: Untreated subtotally nephrectomized group: subtotal (five-sixths) nephrectomy was performed, and 4 weeks later, rats were supplemented with a single I.V. infusion of phosphate buffer solution in the rat tail vein.

Group III: Treated subtotally nephrectomized group: subtotal (five-sixths) nephrectomy was performed, and 4 weeks later, rats were supplemented with a single I.V. infusion of $0.5 \mathrm{ml}$ of phosphate buffer solution (PBS) containing bone marrow-derived stem cells $\left(1.5 \times 10^{6}\right)$ in the rat tail vein with a modified protocol from Yuen et al. (12).

\section{Five-sixths nephrectomy technique}

The 5/6 nephrectomy operation was performed according to methods described by Addis and Lew (13) and was modified to a two-stage operation with removal of one kidney followed, after one week, by excision of the upper and the lower poles of the other kidney using a 2-0 chromic catgut suture loop. Anaesthesia was induced and maintained using a mask containing a cotton pad moistened with ether. The muscle wound was closed with 2-0 chromic catgut thread, and the skin was closed with silk sutures. Bivatracin topical antibiotic spray (ECAP CO., Egypt) was applied to the wound soon after the operation and daily until healing was complete.

\section{Bone marrow-derived stem cell treatment}

Isolation, culture and incubation of BM-MSCs were performed according to McFarlin et al. (14) at the Medical Research Center of Ain Shams University. Bone marrow cells were isolated from the femurs and tibiae of weaned normal male rats aged from 6 to 8 weeks and were suspended in tubes containing $10 \mathrm{ml}$ of complete culture media, Dulbecco's modified Eagles medium (DMEM) (Lonza Company, Swiss).

After centrifugation, the bone marrow cell pellet was suspended in $10 \mathrm{ml}$ of complete culture media in a T-75 flask and incubated at $37^{\circ} \mathrm{C}, 5 \%$ carbon dioxide (CO2) and $85 \%$ humidity. Later, using inverted microscopy, MSCs were identified by their spindle-shaped morphology, adherence and colony-forming capacity. MSCs were distinguished from other bone marrow cells by negative expression of CD34 and positive expression of CD44 in immune staining, as described by $\mathrm{Li}$ et al. (15) (Fig. 1).

The MSC count was determined, and after reaching confluence at day 10, trypsin EDTA was added for $2 \mathrm{~min}$ 


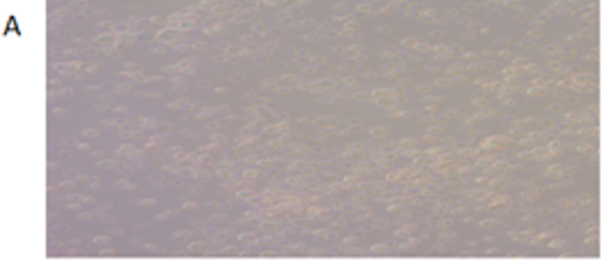

MSCs at Day 1 cells

B

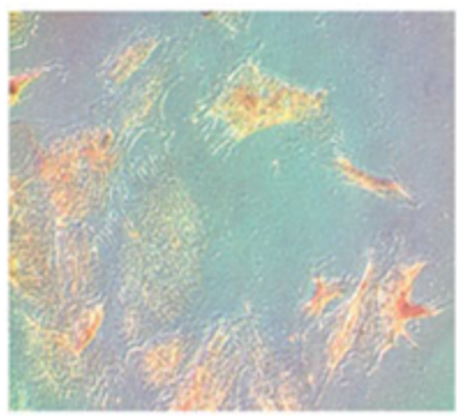

MSCs (CD34 negative expression)

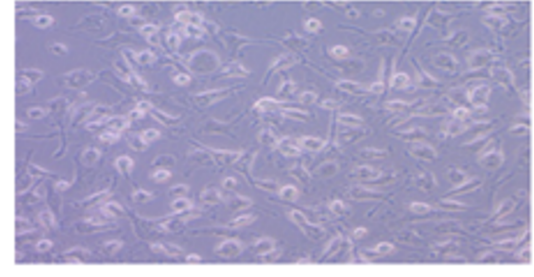

MSCs at Day 8 cells

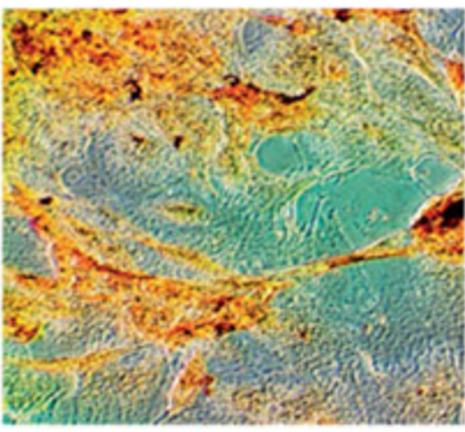

MSCs (CD44 positive expression)
Fig. 1. (A) Bone marrow-derived mesenchymal stem cells at culture days 1 and 8. (B) MSCs show negative expression of $\mathrm{CD} 34$ and positive expression of CD44 (f $400 z \times$ ). at $37^{\circ} \mathrm{C}$ to detach the cells. Trypan blue staining was performed. Viable cells that were not stained with trypan blue were counted using a haemocytometer according to this equation (average number of cells per small square $\times$ dilution factor $\times 10^{4}$ ) (Fig. 1).

\section{Measurement of arterial blood pressure}

Rat arterial blood pressure (systolic, diastolic and mean) was determined using the non-invasive small animal tail blood pressure system (NIBP200A, Biopac systems Inc; USA).

\section{Experimental procedure}

Body weight and arterial blood pressure were measured periodically and at the end of the experimental period (4 weeks after treatment or 8 weeks after nephrectomy or sham operation). Blood pressure was measured using a non-invasive rat tail cuff sphygmomanometer blood pressure system (NIBP200A). On the day of sacrifice, ECG tracing was recorded using bipolar limb leads with a recording speed of $25 \mathrm{~mm} / \mathrm{sec}$ by an ECG recorder (Cardimax Fx-2111, Fukuda Denshi Co., Ltd., Japan). Measurements were made for heart rate, P-R interval, QRS complex voltage and duration, observed Q-T interval (Q-TO) and Q-Tc (the corrected Q-TO for the heart rate effect according to Goldschlager and Goldman (16):

$$
\text { Corrected } \mathrm{Q}-\mathrm{T}\left(\mathrm{Q}-\mathrm{T}_{\mathrm{c}}\right)=\frac{\text { Observed } \mathrm{Q}-\mathrm{T}\left(\mathrm{Q}-\mathrm{T}_{\mathrm{O}}\right)}{\sqrt{\mathrm{R}-\mathrm{R} \text { in seconds }}}
$$

Furthermore, a midline abdominal incision was made to expose and cannulate the abdominal aorta. The collected blood samples were centrifuged, and the separated plasma was then pipetted into clean storage tubes and stored at $-80^{\circ} \mathrm{C}$ for subsequent determination of plasma creatinine and urea levels.

\section{Isolated heart study}

Hearts were excised and perfused in a Langendorff preparation with the standard Krebs-Henselite Bicarbonate (KHB) buffer, $\mathrm{pH} 7.4$, equilibrated with $\mathrm{O} 2$ : $\mathrm{CO} 2$ $(95 \%: 5 \%)$ at $37^{\circ} \mathrm{C}(17)$. After a 20 -min stabilization period, baseline cardiac activities were assessed by recording the heart rate (HR), peak developed tension (PT), time to peak tension (TPT) and half relaxation time (HRT) using an isometric force transducer (UGO BASILE S.R.L., Model 7004-F, Serial N. 101014, Data EVO 14543, Italy) connected with a USB cable to a recorder (UGO BASILE S.R. L. Biological Research Apparatus 21036, Model 17304, Serial N. O448A15, Italy) and to a computer with I Worx LabScribe2 Data Recording and Analysis Software.

An isolated rat heart apex was attached by a clip to a transducer placed vertical to the heart with the distance adjusted to obtain the best recording of tension; the initial tension was $2 \mathrm{gm}$, and then, the transducer was kept in position without change during the whole period of recording. The baseline myocardial flow rate (MFR) and myocardial flow rate per $100 \mathrm{mg}$ of left ventricle (MFR/LV, $\mathrm{ml} / \mathrm{min} / 100 \mathrm{mg}$ ) were recorded.

Then, total global ischaemia was induced by stopping 
the delivery of perfusion fluid to the heart by a stopcock for $30 \mathrm{~min}$. The heart responses, MFR and MFR/LV were recorded at 5, 15 and $30 \mathrm{~min}$ of reperfusion following 30 min of total global ischaemia.

\section{Determination of kidney and heart weights}

Twenty-four hours after renal reperfusion, the left kidneys of each rat and whole heart were washed in normal saline, dried by filter paper and cleaned of fat and fibrous tissue. Cardiac chambers were separated, and all tissues were weighed on a 5-Digit-Metler balance (AE 163). Kidney weight was expressed in (g), and the kidney weight/ body weight $(\mathrm{KW} / \mathrm{BW})$ ratio was calculated. Whole heart and cardiac chamber weights were expressed as absolute values in (mg) as well as cardiac indices (absolute weight/ body weight ratio, in $\mathrm{mg} / \mathrm{g}$ ).

\section{PCR detection of male-derived MSCs}

Genomic DNA was extracted from the rat kidney and heart tissue homogenate in each group using the Wizardt Genomic DNA Purification Kit (Promega, Madison, Wisconsin). The presence or absence of the sex determination region on the male $\mathrm{Y}$ chromosome (sry) gene in recipient female rats was assessed by PCR as previously described (18) to amplify a product of 104 base pairs (bp). PCR products were separated using 2\% agarose gel electrophoresis and stained with ethidium bromide. Positive (rat male genomic DNA) and negative (female rat genomic DNA) controls were included in each assay.

\section{Biochemical analysis}

Serum samples were stored at $-80^{\circ} \mathrm{C}$. Then, using an enzymatic colorimetric technique, we measured serum cre- atinine levels according to the Jaffé reaction (19) and serum urea levels according to the modified Urease Berthelot reaction (20) with kits supplied by Diamond Diagnostics Company, GmbH (Germany).

The results are expressed as the mean \pm standard error and were statistically analysed according to Armitage and Berry (21).

\section{Results}

The results of the present study are displayed in Table $1 \sim 4$ and Fig. 2 4. The results are expressed as the mean \pm SEM.

\section{Changes in body weight percentage and kidney weight}

As shown in Table 1, the body weight percentage change was significantly reduced in untreated subtotally nephrectomized rats compared to sham-operated control rats $(\mathrm{p}<0.01)$, but after stem cell treatment, the body weight percentage change was significantly increased $(p<0.001)$ compared to that in the untreated rats to a level that was not significantly different from that of the control rats. In addition, the remnant kidney tissue weight was increased significantly in the treated subtotally nephrectomized group compared to both the untreated subtotally nephrectomized group and the sham-operated control group $(\mathrm{p}<$ 0.001 for both), indicating that MSCs can decrease cellular apoptosis.

\section{Changes in heart weight values}

Absolute left ventricular weight (LV), LV/BW and $\mathrm{WH} / \mathrm{BW}$ indices were significantly higher in the untreated subtotally nephrectomized group $(\mathrm{p}<0.05 ; \mathrm{p}<0.001$ and

Table 1. The body weight percentage change (BW \%change), kidney tissue weight (mg), heart weights, and serum urea and creatinine $(\mathrm{mg} / \mathrm{dl})$ levels in the three studied groups: sham-operated control (Sham), untreated subtotally nephrectomized (untreated STNx) and treated subtotally nephrectomized (treated STNx) groups

\begin{tabular}{lccc}
\hline & Sham (15) & Untreated STNx (15) & Treated STNx (15) \\
\hline BW\% change & $23.02 \pm 1.21$ & $13.31 \pm 2.61^{\mathrm{a}}$ & $27.61 \pm 1.74^{\mathrm{b}}$ \\
Left kidney remnant weight (mg) & $787.14 \pm 34.35$ & $737.52 \pm 35.69$ & $1047.78 \pm 53.26^{\mathrm{ab}}$ \\
LV (mg) & $518.81 \pm 11.69$ & $569 \pm 16.71^{\mathrm{a}}$ & $588.27 \pm 18.17^{\mathrm{a}}$ \\
LV/BW (mg/gm) & $2.09 \pm 0.05$ & $2.47 \pm 0.08^{\mathrm{a}}$ & $2.30 \pm 0.05^{\mathrm{a}}$ \\
WH/BW (mg/gm) & $3.03 \pm 0.09$ & $3.63 \pm 0.18^{\mathrm{a}}$ & $3.37 \pm 0.08^{\mathrm{a}}$ \\
Creatinine (mg/dl) & $0.47 \pm 0.02$ & $1.17 \pm 0.07^{\mathrm{a}}$ & $0.66 \pm 0.02^{\mathrm{ab}}$ \\
Urea (mg/dl) & $33.54 \pm 1.31$ & $67.15 \pm 3.47^{\mathrm{a}}$ & $42.85 \pm 1.72^{\mathrm{ab}}$ \\
\hline
\end{tabular}

The number of observations is shown in parentheses. All values are expressed as the mean \pm SEM.

a: Significant difference between the untreated subtotally nephrectomized (untreated STNx) group and sham-operated control group (Sham) as calculated by the LSD at $\mathrm{p}<0.05$.

b: Significant difference between the treated subtotally nephrectomized group (treated STNx) group and the untreated subtotally nephrectomized (untreated STNx) group as calculated by the LSD at $\mathrm{p}<0.05$. 
Table 2. Electrocardiographic changes in the three studied groups: sham-operated control (Sham), untreated subtotally nephrectomized (untreated STNx) and treated subtotally nephrectomized (treated STNx) groups

\begin{tabular}{lccc}
\hline & Sham (15) & Untreated STNx (15) & Treated STNx (15) \\
\hline Heart rate (bpm) & $235.67 \pm 5.46$ & $207.43 \pm 12.77^{\mathrm{a}}$ & $232 \pm 4.36^{\mathrm{b}}$ \\
PR interval (msec) & $91.43 \pm 4.04$ & $80 \pm 4.78$ & $104.44 \pm 4.73^{\mathrm{b}}$ \\
QRS duration (msec) & $40 \pm 0$ & $30.48 \pm 2.62^{\mathrm{a}}$ & $40 \pm 0^{\mathrm{b}}$ \\
QRS voltage ( $\mu \mathrm{v})$ & $695.24 \pm 41.68$ & $466.67 \pm 47.97^{\mathrm{a}}$ & $750 \pm 72.87^{\mathrm{b}}$ \\
Q-To (msec) & $129.52 \pm 3.81$ & $172 \pm 6.55^{\mathrm{a}}$ & $137.78 \pm 4.82^{\mathrm{b}}$ \\
Q-Tc (msec) & $258.57 \pm 6.10$ & $323.50 \pm 7.69^{\mathrm{a}}$ & $273.33 \pm 9.53^{\mathrm{b}}$ \\
\hline
\end{tabular}

The number of observations is shown in parentheses. All values are expressed as the mean \pm SEM.

a: Significant difference between the untreated subtotally nephrectomized (untreated STNx) group and sham-operated control group (Sham) as calculated by the LSD at $\mathrm{p}<0.05$.

b: Significant difference between the treated subtotally nephrectomized group (treated STNx) group and the untreated subtotally nephrectomized (untreated STNx) group as calculated by the LSD at $\mathrm{p}<0.05$.

Table 3. Heart rate and Myocardial flow rate $/ 100 \mathrm{mg}$ of left ventricle (MFR/LV, $\mathrm{ml} / \mathrm{min} / 100 \mathrm{mg}$ ), in the three studied groups: sham-operated control (Sham), untreated subtotally nephrectomized (untreated STNx) and treated subtotally nephrectomized (treated STNx) groups

\begin{tabular}{lccc}
\hline & Sham (15) & Untreated STNx (15) & Treated STNx (15) \\
\hline HR (bpm) & $160 \pm 11.88$ & $160.53 \pm 15.34$ & $184.20 \pm 8.56$ \\
Pre-ischaemia baseline & & & $198.53 \pm 14.82^{\mathrm{ab}}$ \\
5 min of reperfusion & $130.93 \pm 15.24$ & $132.13 \pm 14.53$ & $179.80 \pm 13.48^{\mathrm{ab}}$ \\
15 min of reperfusion & $134.07 \pm 9.57$ & $133.87 \pm 15.14$ & $170.53 \pm 15.19^{\mathrm{ab}}$ \\
30 min of reperfusion & $133.33 \pm 10.29$ & $122.60 \pm 14.55$ & $1.20 \pm 0.08$ \\
MFR/LV (ml/min/100 mg) & & $1.10 \pm 0.09$ & $0.96 \pm 0.07^{*}$ \\
Pre-ischaemia baseline & $1.20 \pm 0.16$ & $0.97 \pm 0.08^{*}$ & $0.76 \pm 0.05^{*}$ \\
5 min of reperfusion & $0.89 \pm 0.11^{*}$ & $0.87 \pm 0.09^{*}$ & $0.66 \pm 0.06^{*}$ \\
15 min of reperfusion & $0.78 \pm 0.11^{*}$ & $0.66 \pm 0.06^{*}$ & $0.68 \pm 0.10^{*}$ \\
30 min of reperfusion & 0.68 & \\
\hline
\end{tabular}

*: Significant difference from their initial values as calculated by Student's t-test for paired data.

The number of observations is shown in parentheses. All values are expressed as the mean \pm SEM .

a: Significant difference between the untreated subtotally nephrectomized (untreated STNx) group and sham-operated control group (Sham) as calculated by the LSD at $\mathrm{p}<0.05$.

b: Significant difference between the treated subtotally nephrectomized group (treated STNx) group and the untreated subtotally nephrectomized (untreated STNx) group as calculated by the LSD at $\mathrm{p}<0.05$.

$\mathrm{p}<0.01$, respectively) than in the sham-operated control group, denoting left ventricle hypertrophy. Upon stem cell treatment, both $\mathrm{LV} / \mathrm{BW}$ and $\mathrm{WH} / \mathrm{BW}$ ratios were not significantly decreased compared to those in the untreated nephrectomized group, although those values were still significantly higher than those of the controls (Table 1).

\section{Kidney function tests}

As shown in Table 1, plasma levels of creatinine and urea were significantly elevated in the untreated subtotally nephrectomized group compared to the sham-operated control group ( $\mathrm{p}<0.001$ for both), denoting renal function impairment, whereas following stem cell treatment, those levels were significantly decreased compared to those of the untreated subtotally nephrectomized group $(p<0.001$ for both), although they were still significantly higher than those in the sham-operated control group $(p<0.05$ for both).

\section{Changes in systolic, diastolic and mean arterial blood pressure}

As shown in Fig. 2, systolic, diastolic and mean arterial blood pressure values in nephrectomized rats were significantly increased after 4 weeks $(\mathrm{p}<0.001$ for all) and 8 weeks ( $p<0.001,0.01$ and 0.001 , respectively) compared to the sham-operated control group. Elevated blood pressure reflects deteriorated kidney functions. Stem cell treatment caused a significant decrease in the 8 week values of systolic, diastolic and mean arterial blood pressure compared to those of the untreated subtotally nephrectomized 
Table 4. Peak tension (PT) and peak tension per left ventricular weight (PT/LV), Time to peak tension (TPT), half relaxation time (HRT) and contraction time (CT) in the three studied groups: sham-operated control (Sham), untreated subtotally nephrectomized (untreated STNx) and treated subtotally nephrectomized (treated STNx) groups

\begin{tabular}{|c|c|c|c|}
\hline & Sham (15) & Untreated STNx (15) & Treated STNx (15) \\
\hline PT (gm) & $6.28 \pm 0.26$ & $6.00 \pm 0.22$ & $7.33 \pm 0.42^{\mathrm{ab}}$ \\
\hline \multicolumn{4}{|l|}{ Pre-ischaemia baseline } \\
\hline 5 min of reperfusion & $4.77 \pm 0.33^{*}$ & $4.34 \pm 0.40 *$ & $4.86 \pm 0.29 *$ \\
\hline 15 min of reperfusion & $4.69 \pm 0.39 *$ & $3.84 \pm 0.37 *$ & $4.97 \pm 0.30^{\mathrm{b}} *$ \\
\hline 30 min of reperfusion & $4.29 \pm 0.30^{*}$ & $3.07 \pm 0.29^{\mathrm{a}} *$ & $5.11 \pm 0.30^{\mathrm{ab} *}$ \\
\hline PT/LV (gm/100 mg) & $1.23 \pm 0.30$ & $1.17 \pm 0.27$ & $1.19 \pm 0.35$ \\
\hline \multicolumn{4}{|l|}{ Pre-ischaemia baseline } \\
\hline 5 min of reperfusion & $0.91 \pm 0.28^{*}$ & $0.87 \pm 0.37^{*}$ & $0.79 \pm 0.24 *$ \\
\hline 15 min of reperfusion & $0.91 \pm 0.35 *$ & $0.76 \pm 0.33 *$ & $0.84 \pm 0.29 *$ \\
\hline $30 \mathrm{~min}$ of reperfusion & $0.82 \pm 0.27^{*}$ & $0.60 \pm 0.25^{a *}$ & $0.83 \pm 0.24^{b_{*}}$ \\
\hline TPT (msec) & $113.67 \pm 8.27$ & $120.33 \pm 7.93$ & $89 \pm 2.14^{\mathrm{ab}}$ \\
\hline \multicolumn{4}{|l|}{ Pre-ischaemia baseline } \\
\hline 5 min of reperfusion & $133.67 \pm 11.07$ & $137 \pm 11.75^{*}$ & $91 \pm 3.39^{\mathrm{ab}}$ \\
\hline $15 \mathrm{~min}$ of reperfusion & $110.33 \pm 8.24$ & $150.67 \pm 12.58^{\mathrm{a} *}$ & $91.67 \pm 3.30^{b}$ \\
\hline 30 min of reperfusion & $114.33 \pm 9.17$ & $165.67 \pm 11.61^{\mathrm{a} *}$ & $93.33 \pm 3.44^{b}$ \\
\hline HRT (msec) & $80.67 \pm 7.05$ & $67.33 \pm 5.16$ & $75 \pm 2.84$ \\
\hline \multicolumn{4}{|l|}{ Pre-ischaemia baseline } \\
\hline 5 min of reperfusion & $99.33 \pm 10.75$ & $86.67 \pm 6.70^{*}$ & $86.67 \pm 3.80 *$ \\
\hline $15 \mathrm{~min}$ of reperfusion & $97.67 \pm 7.86$ & $95 \pm 8.31^{*}$ & $85 \pm 2.13^{*}$ \\
\hline 30 min of reperfusion & $94.33 \pm 8.90$ & $103.33 \pm 6.82 *$ & $83.67 \pm 3.67^{\mathrm{b}} *$ \\
\hline $\mathrm{CT}$ (msec) & $194.33 \pm 10.63$ & $184.67 \pm 10.29$ & $164 \pm 3.85^{\mathrm{a}}$ \\
\hline \multicolumn{4}{|l|}{ Pre-ischaemia baseline } \\
\hline 5 min of reperfusion & $233 \pm 15.90$ & $223 \pm 14.97^{*}$ & $177.67 \pm 6.11^{\mathrm{ab}_{*}}$ \\
\hline 15 min of reperfusion & $208 \pm 12.42$ & $243 \pm 15.60^{\mathrm{a} *}$ & $176.67 \pm 3.92^{\mathrm{b} *}$ \\
\hline $30 \mathrm{~min}$ of reperfusion & $208.67 \pm 14.70$ & $269 \pm 12.73^{\mathrm{a} *}$ & $177 \pm 5.60^{b_{*}}$ \\
\hline
\end{tabular}

The number of observations is shown in parentheses. All values are expressed as the mean \pm SEM.

a: Significant difference between the untreated subtotally nephrectomized (untreated STNx) group and sham-operated control group (Sham) as calculated by the LSD at $\mathrm{p}<0.05$.

b: Significant difference between the treated subtotally nephrectomized group (treated STNx) group and the untreated subtotally nephrectomized (untreated STNx) group as calculated by the LSD at $p<0.05$.

*: Significant difference from their initial values as calculated by Student's t-test for paired data.

rats $(\mathrm{p}<0.001, \mathrm{p}<0.05$ and $\mathrm{p}<0.001$, respectively).

A significant positive correlation was detected between serum creatinine and systolic and diastolic blood pressure $(\mathrm{p}<0.001, \mathrm{p}<0.05)$.

\section{Electrocardiographic changes}

Table 2 shows that in untreated nephrectomized rats, $\mathrm{HR}, \mathrm{QRS}$ duration and voltage were significantly reduced $(\mathrm{p}<0.05, \mathrm{p}<0.001$ and $\mathrm{p}<0.01)$ while Q-To and Q-Tc intervals were prolonged ( $\mathrm{p}<0.001$ for both) compared to those in the control group. Stem cell treatment significantly increased the HR $(p<0.05)$, prolonged the PR interval and QRS duration and increased QRS voltage ( $p$ $<0.001$ for all) as well as significantly shortened the Q-To and Q-Tc intervals ( $\mathrm{p}<0.001$ for both) compared to those in untreated nephrectomized rats.

\section{Isolated perfused hearts studies}

Chronotropic activity is illustrated in Table 3, in which the treated subtotally nephrectomized group showed a significant increase in $\mathrm{HR}$ values at 5, 15 and $30 \mathrm{~min}$ of reperfusion compared to both untreated subtotally nephrectomized rats and sham-operated control rats $(\mathrm{p}<0.01,<$ 0.05 and $<0.05$, respectively, for both).

\section{Inotropic activity is illustrated in Table 4}

Compared to the pre-ischaemia baseline values, PT and peak tension per left ventricular weight $(\mathrm{PT} / \mathrm{LV})$ values were significantly decreased $(\mathrm{p}<0.001)$ in all studied groups at 5, 15 and $30 \mathrm{~min}$ of reperfusion, while the TPT, HRT and contraction time (CT) were all significantly prolonged in the untreated nephrectomized group compared to the other groups $(\mathrm{p}<0.05,0.01$ and 0.001 for all, re- 


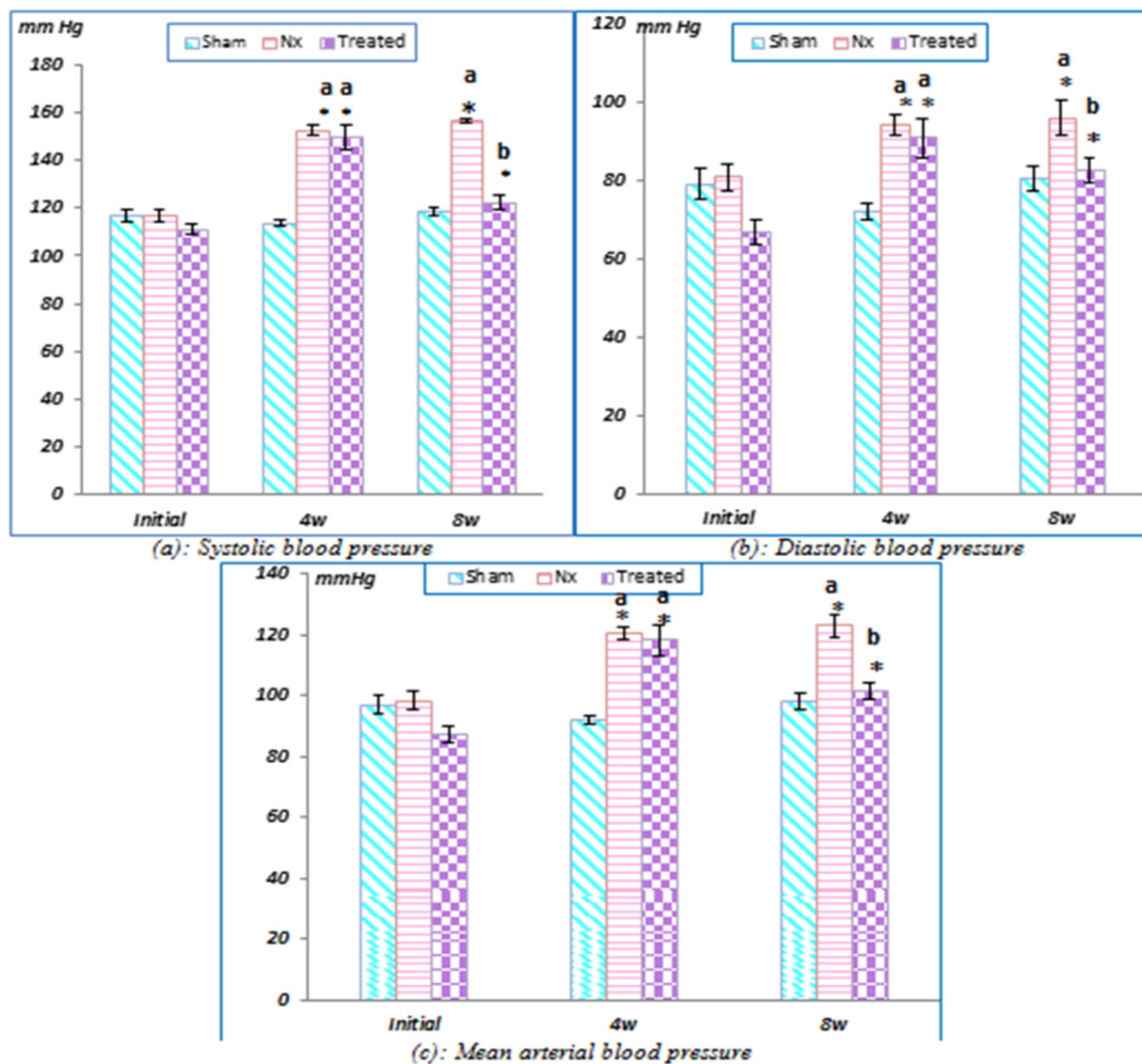

Fig. 2. Initial, 4-week and 8-week (a) systolic blood pressure (SBP), (b) diastolic blood pressure and (c) mean arterial blood pressure values in the three studied groups. *: Significant difference compared to their initial values as calculated by Student's t-test for paired data. a: Significant difference compared to the sham-operated control (Sham) group as calculated by the LSD at $p<0.05$. b: Significant difference compared to the untreated subtotally nephrectomized (untreated STNx) group as calculated by the LSD at $p<0.05$.

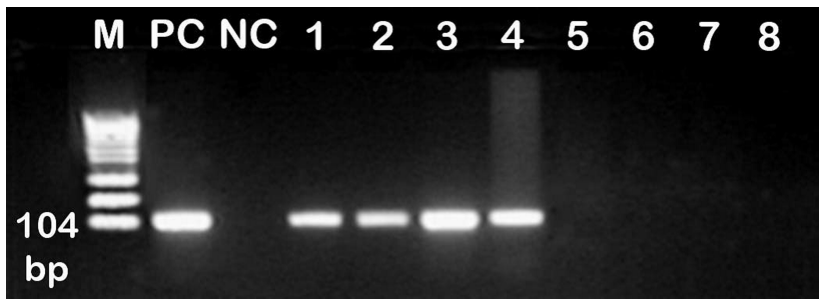

Fig. 3. Results of the PCR assay for the male $Y$ chromosome (sry) gene following $2 \%$ agarose gel electrophoresis and staining with ethidium bromide. M: DNA 100-bp marker, PC: positive PCR control (male rat genomic DNA), NC: negative PCR control (female rat genomic DNA). Lane 1 4: MSC-treated group, which was injected with mesenchymal stem cells (MSCs). Lane 5 8: Control and untreated groups that were not injected with male MSCs.

spectively).

As shown in Table 4, the PT and PT/LV values after 30 min of reperfusion $(p<0.01$ and $p<0.05$ for both, respectively) were significantly decreased in untreated nephrectomized rats compared to the sham-operated control rats. Compared to those in the untreated group, stem cell treatment significantly increased the PT values at pre-ischaemia baseline and after 15 and $30 \mathrm{~min}$ of reperfusion $(\mathrm{p}<0.01, \mathrm{p}<0.05$ and $\mathrm{p}<0.001)$ and the PT/LV value a $30 \mathrm{~min}$ of reperfusion $(\mathrm{p}<0.05)$

As shown in Table 4, the TPT and CT were significantly prolonged in the untreated nephrectomized group at 15 and $30 \mathrm{~min}$ of reperfusion $(\mathrm{p}<0.01, \mathrm{p}<0.001$ and $\mathrm{p}<0.05, \mathrm{p}<0.01$, respectively), but stem cell treatment significantly shortened all TPT values $(p<0.01, p<$ $0.01, \mathrm{p}<0.001$ and $\mathrm{p}<0.001)$, the half relaxation value at 30 min of reperfusion $(\mathrm{p}<0.05)$ and the CT values at 15 and $30 \mathrm{~min}$ of reperfusion $(\mathrm{p}<0.001$ for both).

\section{Myocardial flow rate}

In all the studied groups, there were significant decreases in the MFR and MFR/LV at 5, 15 and $30 \mathrm{~min}$ of reperfusion compared to their baseline pre-ischaemia values, as shown in Table 3 .

\section{PCR detection of male-derived MSCs}

The 104-bp band of the Y chromosome marker (sry gene) was expressed in the kidney and the heart homogenate of the treated female rats, assuring BM-MSC homing to these tissues (Fig. 3). 

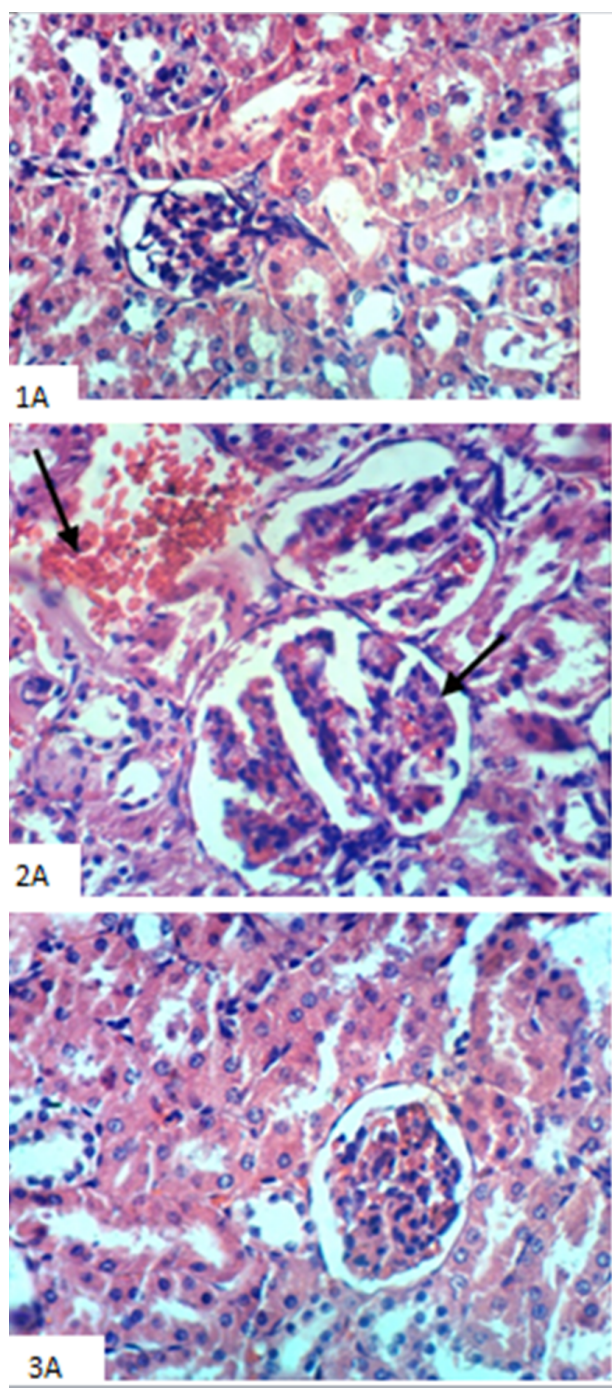
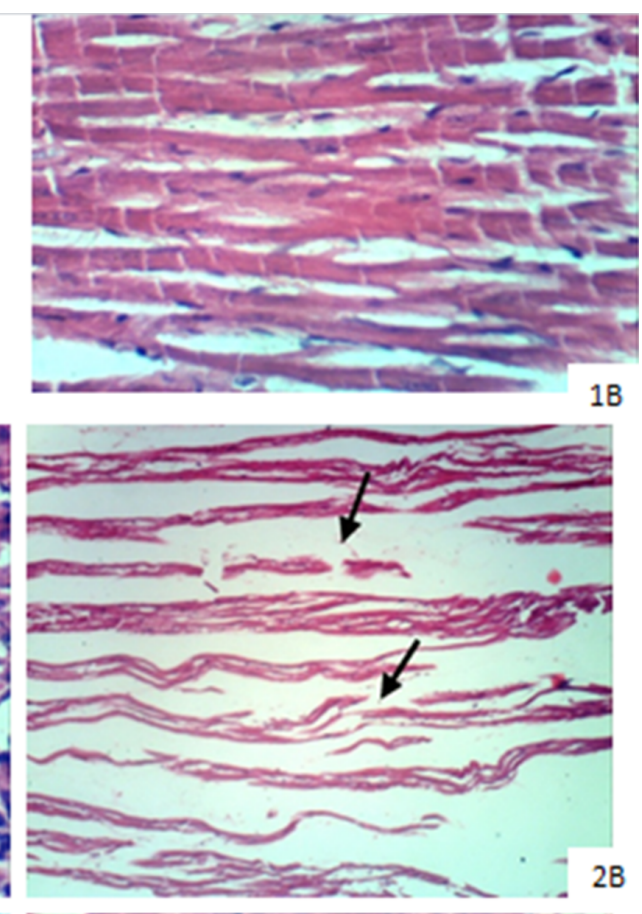

$2 B$
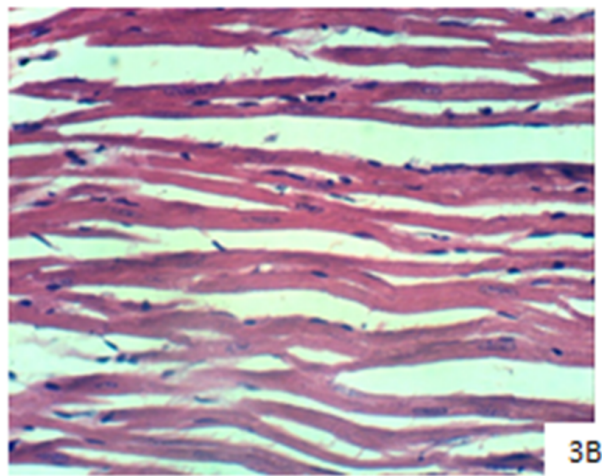

Fig. 4. Histopathological changes in 1-Control group: (A) Renal tissues (B) Cardiac muscles. 2-Untreated nephrectomised group (A) Renal tissues showing hypertrophy of the glomerular tufts and congestion of renal blood vessels (B) Cardiac muscle showing intramuscular oedema that caused dispersion of the cardiomyocytes. 3-MSCs treated group (A) Renal tissues showing apparent normal renal parenchyma (B) Cardiac muscles showing regained normal morphology $(\mathrm{H} \& \mathrm{E} \times 400)$.

\section{Histopathological examination}

Renal parenchyma: As shown in Figure 4, untreated rat kidney sections revealed hypertrophied and congested glomerular tufts with distended Bowman's space together with atrophy of other glomerular tufts. Additionally, there was evident cystic dilatation and distension with proteinaceous material in some renal tubules accompanied by necrosis of other renal tubules. Additionally, renal blood vessels showed marked congestion.

Following treatment, the examined kidney sections revealed a decrease in glomerular hypertrophy with normal renal parenchyma

Cardiac tissue: Analysis of heart sections showed that the heart of sham control rats contained normal cardiomyocytes. In contrast, the hearts of rats from the untreated group showed intermuscular oedema that resulted in dispersed cardiomyocytes and minor intermuscular in- flammatory cell infiltration. However, rat cardiomyocytes from the treated group revealed no histopathological changes compared with normal cardiomyocytes (Fig. 4).

\section{Discussion}

The present study portrayed the effect of BM-MSCs on renal and cardiovascular functions in adult rats with established CKD.

In the current study, 5/6 nephrectomy induced renal damage, as evidenced by the significant elevation in plasma urea and creatinine levels and all arterial blood pressure values. Renal damage was confirmed by renal glomeruli and tubule necrosis with compensatory hypertrophy of the remaining glomeruli and tubules, which was similar to the findings by Yuen et al. (12).

The ensuing uremic state after 5/6 nephrectomy caused 
anorexia and hyperleptinemia (22) and inhibited downstream growth hormone signalling (23), leading to the inability of nephrectomized rats to gain weight, as evidenced by a significant reduction in body weight and its percentage change compared to those of the sham-operated control group.

The pro-inflammatory factors TNF- $\alpha$, IL-1 and IL-6 and pro-fibrotic, anti-angiogenic factors Ang $I I$ and reactive oxygen species (ROS) that accompany the uremic state alter endothelial permeability, resulting in endothelial dysfunction. In conjunction with impaired sodium and water excretion, impaired calcium metabolism can elevate blood pressure, leading to ventricular remodelling and hypertrophy (24). This sequence of events was recorded in this study, in which LV/BW and WH/BW ratios showed a significant increase in the nephrectomized group compared to the control group. In addition, dispersed cardiomyocytes with intramuscular oedema and slight inflammatory cell infiltration was observed.

Moreover, compared to the sham-operated group, the untreated nephrectomized group showed significant decreases in HR, QRS voltage and QRS duration as well as significant prolongation of the Q-To and Q-Tc intervals.

Bradycardia may be the result of the baroreceptor reflex in response to the high arterial blood pressure according to Mary's law or the result of a synergistic action of hyperkalaemia and uremic toxins (25). A significantly low QRS voltage may result from ischaemia that follows cardiac hypertrophy (26).

The detected Q-T interval prolongation reflects a combination of hypocalcaemia and increased left ventricular mass arising from chronic hypertension (27) or may result from gap junction disruption by the pro-fibrotic uremic toxins (28).

The studied isolated hearts subjected to ischaemia-reperfusion injury showed a decrease in all reperfusion PT, peak tension per left ventricular weight (PT/LV) and MFR values together with prolonged TPT, HRTs and CTs following reperfusion compared to the pre-ischaemia baseline values in all groups and when comparing untreated nephrectomized rats with sham-operated control rats. This observation suggests systolic and diastolic function impairment following ischaemia-reperfusion, especially in untreated nephrectomized rats.

Impaired systolic and diastolic function can be attributed to mitochondrial dysfunction, excess ROS generation and calcium overload concomitant with decreased responsiveness of contractile elements to calcium (calcium paradox) (29). In addition, following reperfusion, the $\mathrm{pH}$ paradox activates calpains that lead to myofibril proteol- ysis and alter membrane ion channel activity, leading to myocardial stunning (30). MFR reduction can be explained by atherosclerosis and calcification of coronary arteries in patients with end stage renal disease (31).

Both systolic and diastolic dysfunction are exacerbated by uraemia, reflecting organ cross-talk, as reported by Yuen et al. (12), whom demonstrated an elevated left ventricular end-diastolic pressure volume relationship (LV EDPVR) in nephrectomized rats, indicating diastolic dysfunction.

Diastolic dysfunction can result from uremic myocardial remodelling and disturbed myocardial calcium homeostasis (32). In addition, electrolyte disturbances, uremic toxins and pro-inflammatory cytokines can exert a negative inotropic effect or induce cardiomyocyte apoptosis (33).

Four weeks following a single BM-MSC injection, plasma urea and creatinine levels and all arterial blood pressure values were significantly decreased, with partial improvement in renal parenchyma histological appearance and a significant increase in the body weight gain percentage change, similar to the results of Abdel Aziz et al. (34).

Moreover, MSCs modulated cardiac electrophysiological properties, as they significantly increased the HR, P-R interval, QRS voltage and QRS duration and shortened the Q-To and Q-Tc intervals compared to those in the untreated group. Additionally, MSCs improved the chronotropic heart state, as they significantly increased the in vitro recorded $\mathrm{HR}$.

In addition, the significant increase from the pre-ischaemia baseline to the reperfusion values of the PT and PT/ LV together with the significant shortening in reperfusion TPT, half relaxation and CT values denotes improved systolic and diastolic function, similar to the report by Yuen et al. (12).

The ability of BM-MSCs to restore normal renal and cardiac function may be explained by their ability to selectively migrate to and home into injured tissues, as BM-MSCs express receptors for growth factors and chemokines released from inflamed organs (35).

In the injured organs, BM-MSCs can trans-differentiate into many tissues, such as tubular epithelium, renal mesangial cells, podocytes or even glomerular endothelial cells as well as cardiomyocytes and blood vessel elements (36). Alternatively, BM-MSCs can fuse with host cells, as reported by Ly and Nattel (37), whom detected cardiomyocyte-specific markers in MSCs, suggesting electrical coupling of MSCs with native cardiomyocytes, which may reduce the risk of ventricular arrhythmia. Moreover, MSCs have paracrine effects, as they can secrete 
growth, angiogenic and mitogenic factors such as vascular endothelial growth factor (VEGF), hepatocyte growth factor (HGF), and IGF-I together with anti-apoptotic and anti-fibrotic factors such as IL-10 and Bc1-2 (34).

In addition, BM-MSCs show anti-inflammatory and immunosuppressive effects because they can impair the maturation and function of dendritic cells and B-cells and suppress T-cell proliferation and can downregulate pro-inflammatory cytokines such as IL-1 $\beta$ and TNF- $\alpha$ (34). Ayatollahi et al. (38) also highlighted the antioxidant properties of BM-MSCs, which are able to reduce tissue malondialdehyde (MDA) and increase the levels of the antioxidants superoxide dismutase (SOD) and glutathione peroxidase (GSH-Px).

Moreover, MSCs may release extracellular vesicles (EVs) known as exosomes, which deliver genes, microRNAs and proteins to recipient cells, mediating MSC paracrine actions (39).

On the other hand, while a single MSC injection increased the MFR, the difference was not significant; this result may be explained by Papazova et al. (40), whom postulated that multiple administrations of stem cells would confer benefits over single administration for chronic conditions.

\section{Conclusions}

In summary, this study highlighted the potential ability of BM-MSC injection to halt CKD progression, as evidenced by decreased serum urea and creatinine levels and arterial blood pressure after BM-MSC treatment. These data were also supported by the reduction in glomerular hypertrophy. Furthermore, BM-MSCs can improve cardiac electrophysiological properties, as evidenced by the significant increase in QRS voltage and decrease in the QT interval. Additionally, the cardiac inotropic functions were improved; the improvement in systolic function evidenced by increased PT per left ventricular weight and decreased time to peak tension, and the improvement in diastolic function was evidenced by the shortening of the TPT. These data were also supported by the restoration of relatively normal cardiac myocyte morphology, as shown by histopathological examination of cardiac tissue in stem cell-treated nephrectomized rats. Thus, BM-MSCs, due to their proven anti-hypertensive and anti-arrhythmic properties, could have strong therapeutic potential.

\section{Acknowledgments}

Authors wish to acknowledge the Egyptian Knowledge Bank for facilitating the language editing process for this article via Springer-Nature.

\section{Potential Conflict of Interest}

The authors have no conflicting financial interest.

\section{References}

1. Hill NR, Fatoba ST, Oke JL, Hirst JA, O'Callaghan CA, Lasserson DS, Hobbs FD. Global prevalence of chronic kidney disease - a systematic review and meta-analysis. PLoS One 2016;11:e158765

2. Efstratiadis G, Divani M, Katsioulis E, Vergoulas G. Renal fibrosis. Hippokratia 2009;13:224-229

3. Granata S, Zaza G, Simone S, Villani G, Latorre D, Pontrelli P, Carella M, Schena FP, Grandaliano G, Pertosa G. Mitochondrial dysregulation and oxidative stress in patients with chronic kidney disease. BMC Genomics 2009;10: 388

4. Briet M, Burns KD. Chronic kidney disease and vascular remodelling: molecular mechanisms and clinical implications. Clin Sci (Lond) 2012;123:399-416

5. Roemeling-van Rhijn M, Reinders ME, de Klein A, Douben H, Korevaar SS, Mensah FK, Dor FJ, IJzermans JN, Betjes MG, Baan CC, Weimar W, Hoogduijn MJ. Mesenchymal stem cells derived from adipose tissue are not affected by renal disease. Kidney Int 2012;82:748-758

6. Kunter U, Rong S, Moeller MJ, Floege J. Mesenchymal stem cells as a therapeutic approach to glomerular diseases: benefits and risks. Kidney Int Suppl (2011) 2011;1:68-73

7. Murphy MB, Moncivais K, Caplan AI. Mesenchymal stem cells: environmentally responsive therapeutics for regenerative medicine. Exp Mol Med 2013;45:e54

8. Morigi $M$, Introna $M$, Imberti $B$, Corna $D$, Abbate $M$, Rota C, Rottoli D, Benigni A, Perico N, Zoja C, Rambaldi A, Remuzzi A, Remuzzi G. Human bone marrow mesenchymal stem cells accelerate recovery of acute renal injury and prolong survival in mice. Stem Cells 2008;26:2075-2082

9. Villanueva S, Ewertz E, Carrión F, Tapia A, Vergara C, Céspedes C, Sáez PJ, Luz P, Irarrázabal C, Carreño JE, Figueroa F, Vio CP. Mesenchymal stem cell injection ameliorates chronic renal failure in a rat model. Clin Sci (Lond) 2011;121:489-499

10. Gheisari Y, Ahmadbeigi N, Naderi M, Nassiri SM, Nadri S, Soleimani M. Stem cell-conditioned medium does not protect against kidney failure. Cell Biol Int 2011;35:209-213

11. Huuskes BM, Wise AF, Cox AJ, Lim EX, Payne NL, Kelly DJ, Samuel CS, Ricardo SD. Combination therapy of mesenchymal stem cells and serelaxin effectively attenuates renal fibrosis in obstructive nephropathy. FASEB J 2015;29: 540-553

12. Yuen DA, Connelly KA, Advani A, Liao C, Kuliszewski MA, Trogadis J, Thai K, Advani SL, Zhang Y, Kelly DJ, Leong-Poi H, Keating A, Marsden PA, Stewart DJ, Gilbert RE. Culture-modified bone marrow cells attenuate cardiac and renal injury in a chronic kidney disease rat model via a novel antifibrotic mechanism. PLoS One 2010;5:e9543 
13. Addis T, Lew W. The restoration of lost organ tissue : the rate and degree of restoration. J Exp Med 1940;71:325-333

14. McFarlin K, Gao X, Liu YB, Dulchavsky DS, Kwon D, Arbab AS, Bansal M, Li Y, Chopp M, Dulchavsky SA, Gautam SC. Bone marrow-derived mesenchymal stromal cells accelerate wound healing in the rat. Wound Repair Regen 2006;14:471-478

15. Li H, Fu X, Ouyang Y, Cai C, Wang J, Sun T. Adult bone-marrow-derived mesenchymal stem cells contribute to wound healing of skin appendages. Cell Tissue Res 2006; 326:725-736

16. Goldschlager N, Goldman MJ. Electrocardiography: essentials of interpretation. Los Altos, California: Lang Medical Publications; 1984. 13-18

17. Ayobe $\mathrm{MH}$, Tarazi RC. Beta-Receptors and contractile reserve in left ventricular hypertrophy. Hypertension 1983;5: I192-I197

18. Abdel Aziz MT, Atta HM, Mahfouz S, Fouad HH, Roshdy NK, Ahmed HH, Rashed LA, Sabry D, Hassouna AA, Hasan NM. Therapeutic potential of bone marrow-derived mesenchymal stem cells on experimental liver fibrosis. Clin Biochem 2007;40:893-899

19. Tietz NW. Clinical guide to laboratory tests. 3rd ed. Philadelphia: W.B. Saunders; 1995

20. Young DS. Effects of drugs on clinical laboratory tests. 4th ed. Washington: AACC Press; 1995

21. Armitage P, Berry G. Statistical methods in medical research. 2nd ed. London: Blackwell Scientific Publications; 1987

22. Nagy K, Nagaraju SP, Rhee CM, Mathe Z, Molnar MZ. Adipocytokines in renal transplant recipients. Clin Kidney J 2016;9:359-373

23. Garibotto G, Russo R, Sofia A, Ferone D, Fiorini F, Cappelli V, Tarroni A, Gandolfo MT, Vigo E, Valli A, Arvigo M, Verzola D, Ravera G, Minuto F. Effects of uremia and inflammation on growth hormone resistance in patients with chronic kidney diseases. Kidney Int 2008;74: 937-945

24. Yisireyili M, Shimizu H, Saito S, Enomoto A, Nishijima F, Niwa T. Indoxyl sulfate promotes cardiac fibrosis with enhanced oxidative stress in hypertensive rats. Life Sci 2013;92:1180-1185

25. Choi DH, Ahn SH, Jung SW, Lee YM, Kim HJ, Lee MS, Baek SH, Song JH. Clinical characteristics of patients with chronic kidney disease associated with marked bradycardia. Korean J Nephrol 2004;23:256-262

26. Madias JE. Low QRS voltage and its causes. J Electrocardiol 2008;41:498-500

27. El-Sherif N, Turitto G. Electrolyte disorders and arrhythmogenesis. Cardiol J 2011;18:233-245
28. Tang WH, Wang CP, Chung FM, Huang LL, Yu TH, Hung WC, Lu LF, Chen PY, Luo CH, Lee KT, Lee YJ, Lai WT. Uremic retention solute indoxyl sulfate level is associated with prolonged QTc interval in early CKD patients. PLoS One 2015;10:e0119545

29. Turer AT, Hill JA. Pathogenesis of myocardial ischemia-reperfusion injury and rationale for therapy. Am J Cardiol 2010;106:360-368

30. Kalogeris T, Baines CP, Krenz M, Korthuis RJ. Cell biology of ischemia/reperfusion injury. Int Rev Cell Mol Biol 2012;298:229-317

31. Schwarz U, Buzello M, Ritz E, Stein G, Raabe G, Wiest G, Mall G, Amann K. Morphology of coronary atherosclerotic lesions in patients with end-stage renal failure. Nephrol Dial Transplant 2000;15:218-223

32. Cannavo A, Liccardo D, Koch WJ. Targeting cardiac $\beta$ -adrenergic signaling via GRK2 inhibition for heart failure therapy. Front Physiol 2013;4:264

33. Bombardini T, Zoppè M, Ciampi Q, Cortigiani L, Agricola E, Salvadori S, Loni T, Pratali L, Picano E. Myocardial contractility in the stress echo lab: from pathophysiological toy to clinical tool. Cardiovasc Ultrasound 2013;11:41

34. Abdel Aziz MT, Wassef MA, Ahmed HH, Rashed L, Mahfouz S, Aly MI, Hussein RE, Abdelaziz M. The role of bone marrow derived-mesenchymal stem cells in attenuation of kidney function in rats with diabetic nephropathy. Diabetol Metab Syndr 2014;6:34

35. Baglio SR, Pegtel DM, Baldini N. Mesenchymal stem cell secreted vesicles provide novel opportunities in (stem) cell-free therapy. Front Physiol 2012;3:359

36. Quevedo HC, Hatzistergos KE, Oskouei BN, Feigenbaum GS, Rodriguez JE, Valdes D, Pattany PM, Zambrano JP, $\mathrm{Hu} \mathrm{Q}, \mathrm{McNiece}$ I, Heldman AW, Hare JM. Allogeneic mesenchymal stem cells restore cardiac function in chronic ischemic cardiomyopathy via trilineage differentiating capacity. Proc Natl Acad Sci U S A 2009;106:14022-14027

37. Ly HQ Nattel S. Stem cells are not proarrhythmic: letting the genie out of the bottle. Circulation 2009;119:1824-1831

38. Ayatollahi M, Hesami Z, Jamshidzadeh A, Gramizadeh B. Antioxidant effects of bone marrow mesenchymal stem cell against carbon tetrachloride-induced oxidative damage in rat livers. Int J Organ Transplant Med 2014;5:166-173

39. Nargesi AA, Lerman LO, Eirin A. Mesenchymal stem cell-derived extracellular vesicles for renal repair. Curr Gene Ther 2017;17:29-42

40. Papazova DA, Oosterhuis NR, Gremmels H, van Koppen A, Joles JA, Verhaar MC. Cell-based therapies for experimental chronic kidney disease: a systematic review and meta-analysis. Dis Model Mech 2015;8:281-293 